\title{
Treatment Approach for an Infant with Complex Congenitally Corrected Transposition of the Great Arteries
}

\author{
Nedim Begic ${ }^{1}, Z i j o$ Begic ${ }^{1 a}$, Edin Medjedovic ${ }^{2}$, Edin Begic $^{3}$ \\ ${ }^{1}$ Department of Cardiology, Pediatric Clinic, Clinical Center University of Sarajevo, Sarajevo, Bosnia and Herzegovina, ${ }^{2}$ Clinic \\ of Gynecology and Obstetrics, Clinical Center University of Sarajevo, Sarajevo, Bosnia and Herzegovina, ${ }^{3}$ Department of \\ Cardiology, General Hospital "Prim. dr. Abdulah Nakaš", Sarajevo, Bosnia and Herzegovina
}

Correspondence: begiczijo@gmail.com; Tel.: + 38761338 096; Fax: + 38733566525

Received: July 20, 2020; Accepted: December 22, 2020

Objective - The aim of the paper is to present a rare and complex congenital heart defect (CHD), congenitally corrected transposition of the great arteries of the heart (ccTGA) with associated anomalies, including ventricular septal defect (VSD), valvular and subvalvular pulmonary stenosis, dysplasia of the tricuspid valve, and atrial septal defect (ASD) with first-degree atrioventricular block, which was diagnosed, monitored and successfully treated with heart surgery in an infant. Case Report - A female infant was born with 3350 grams in weight, $50 \mathrm{~cm}$ in length, oxygen saturation of $98 \%$, and heart rate of 170 beats per minute. The antenatal and perinatal period was normal. CHD was verified by ultrasound at the age of 3 days. Angiotensin-converting-enzyme inhibitors (ACE inhibitors) and diuretics were introduced in therapy after one month. Cardiac surgery (Senning-Rastelli procedure with placement of an 18-mm Contegra conduit) was performed at the age of 9 months. After the operation, the infant was stable on therapy with diuretics, antiaggregants, beta blockers, and antianemic therapy with vitamin D in prophylaxis. Conclusion - ccTGA with associated anomalies is a rare, life-threatening, congenital heart disease. After birth it demands correct diagnosis, adequate follow-up, and cardiac surgery in infancy.

Key Words: Congenital Heart Defects • Cardiology • Treatment, Transposition • Great Arteries.

\section{Introduction}

Modern pediatric cardiology mostly deals with congenital heart defects (CHD) which comprise one quarter of all congenital anomalies (1-3). CHDs are divided into anomalies with a left-right shunt or right-left shunt, obstructive anomalies and complex anomalies (1-3). Complex anomalies account for $20 \%$ of all CHDs and they are very difficult to diagnose, demanding in terms of follow-up, and risky for surgical treatment (palliation, radical surgeries, hybrid surgeries and anatomical and physiological correction) (4). The incidence of CHDs is around $1 \%(1.2 \%$ to $1.4 \%)$ Congenitally corrected transposition of the great arteries (ccTGA) is

${ }^{\mathrm{a}}$ ORCID ID: https://orcid.org/0000-0002-1863-5755. a $\mathrm{CHD}$ which comprises less than $1 \%$ of all CHDs, and ccTGA with associated anomalies is even more rare (5). Although simple ccTGA might be asymptomatic up to the sixth decade of life, complex ccTGA can be a life-threatening CHD, requiring surgical treatment in infancy. The aim of this paper is to present a treatment approach to a rare CHD (ccTGA), with the following associated anomalies: a wide outlet ventricular septal defect (VSD), valvular and subvalvular pulmonary stenosis, dysplasia of the tricuspid valve, atrial septal defect (ASD), and atrioventricular (AV) block.

\section{Case Report}

A female infant was born with 3350 grams in weight, $50 \mathrm{~cm}$ in length, oxygen saturation of $98 \%$, 
and heart rate of 170 beats per minute. The antenatal and perinatal period was normal. Family history was unremarkable. CHD was discovered upon ultrasound at the age of 3 days. Angiotensin-converting-enzyme inhibitors (ACE inhibitors) and diuretics were introduced in therapy after one month. During the follow-up, the infant failed to thrive, and was periodically tachydispnoic, with relatively frequent respiratory difficulties and upper respiratory tract infections. Due to technical reasons, the infant could not undergo surgical correction in Sarajevo, so at the age of 9 months, she was transferred to Istanbul, Turkey, where the surgical procedure was performed. At the time of transport, her body weight was 5510 grams, pulse 160-186 beats per minute, and oxygen saturation 92 to $96 \%$. Ictus inconspicuous, without thrill, heart action rhythmic, clear tones with systolic murmur over the mesocardium III/VI. Hepatomegaly was not verified. Electrocardiogram showed sinus rhythm with frequency about 150 beats per minute, left axis deviation, with incomplete right bundle branch block. There was a bidirectional low-velocity flow through the VSD, and a pressure gradient of $90 \mathrm{mmHg}$ across the pulmonary artery. There was a 3-mm wide ostium secundum ASD and mild dysplasia of the tricuspid valve, but without significant tricuspid regurgitation. The Senning-Rastelli procedure using an 18mm Contegra conduit (Contegra, Medtronic, Inc., Minneapolis) was performed. The left atrial appendage was used to form a new interatrial septum, with closure of the wide VSD with a Dacron patch, by making an intracardiac tunnel between the left ventricle and the aorta. An artificial valve conduit was inserted between the right ventricle and the pulmonary artery (to resolve pulmonary stenosis). The child was transferred to the intensive care unit in a stable hemodynamic state. Sinus rhythm was established on the first postoperative day, and the child was extubated on the second postoperative day. After two days, the infant was transferred to the Department of Cardiology, and on the tenth day she was discharged home. After the operation, the infant was stable on therapy with diuretics, antiaggregants, beta blockers, and antianemic therapy. After four to six weeks, therapy was withdrawn except for the antiplatelet drug (acetylsalicylic acid at a dose of $3-5 \mathrm{mg} / \mathrm{kg}$ of body weight).

\section{Discussion}

Although it can be detected earlier, it would be optimal to do fetal echocardiography at the time of 20 weeks' pregnancy $(5,6,7)$. Suspicion of a complex CHD is likely to enable better preparation for more adequate neonatal care, and postnatal follow-up. The Senning and Rastelli procedure was performed for the first time in Turkey on this patient. In the United States of America surgery for this type of anomaly has been performed at the Children's Medical Center, Dallas, where in 19 surgically corrected patients, 7 had associated VSD and pulmonary stenosis (8). The results of treatment were quite good, taking into account the complexity of the disease (mortality of $5 \%$ and an implanted pacemaker in $26 \%$ of patients with relatively good biventricular function) (8). In a ccTGA with VSD and severe pulmonary stenosis, it is also possible to perform a double switch procedure in which, instead of the arterial switch, a Rastelli procedure is performed, along with atrial switch Senning.-These types of operations are performed after the 6th month of life $(7,8)$. In the present report, the infant did not have tricuspid regurgitation postoperatively. Tricuspid regurgitation begins to develop most frequently in the second decade of life, and hemodynamic overload usually happens in the third decade of life (8). According to Boston Children's Hospital, survival, without the need for right ventricular surgery, ranges from $84 \%, 75 \%, 68 \%, 61 \%$ in the period from the first, fifth, tenth and fifteenth year of life (9). There was no need for right ventricular surgery in $43 \%$ of patients for 15 years of life (9). Graham et al. found that earlier surgical management of these patients, before ventricular dysfunction becomes prominent, should be incorporated into management in an attempt to improve long-term outcome (10). It is likely that in the case of progressive tricuspid insufficiency, replacement of the tricuspid valve will probably be indicated, and the time of decision will depend on the function of the right ventricle. Right ventricular function is one of the 
most important predictor parameters for morbidity and mortality in patients who undergo early cardiac surgery for a complex CHD $(8,10,11)$. Probably the defect should have been surgically corrected earlier due to the low body weight and the size of the VSD, and the flow through the VSD. The good side of the CHD was probably the existing valvular and subvalvular stenosis that acted protectively against pulmonary hypertension development. On the one hand, the hemodynamics of the ccTGA, and on the other hand, the wide VSD with the leftright shunt across it, and inverse chambers with the pulmonary artery obstruction did not give the possibility of any other choice. It is possible that beta blockers should have been introduced to therapy in the preoperative period, although arrhythmias were not recorded. The main advantage of the combined Rastelli procedure and atrial switch (Senning) is that the left ventricle is finally connected to the aorta via the intracardiac tunnel, while the earlier systemic right ventricle is reconnected to the pulmonary circulation in which is pressure is low. Postoperative complications are in the form of arrhythmias, with possible complete atrioventricular block, along with right heart failure. This child will later need cardiosurgical replacement of the conduit, because due to growth and degeneration of the xenograft, progressive obstruction of the pulmonary valved conduit will develop.

\section{Conclusion}

ccTGA with associated anomalies is a rare, life threatening CHD. After birth it demands correct diagnosis, adequate follow-up and cardiosurgical treatment in infancy. It is of paramount importance to improve the pediatric cardiac surgery service in our country to provide adequate and timely care for the most difficult pediatric CHD cases.

Authors' Contributions: Conception and design: NB and EB; Acquisition, analysis and interpretation of data: ZB, NB, EM and $\mathrm{EB}$; Drafting the article: $\mathrm{EB}$ and $\mathrm{ZB}$; Revising the article critically for intellectual content: ZB, NB, EM and EB; Approved final version of the manuscript: $\mathrm{ZB}, \mathrm{NB}, \mathrm{EM}$ and $\mathrm{EB}$.

Conflict of Interest: The authors declare no conflict of interest. This case report was partly presented at the 8 th Congress of Cardiologists and Angiologists of Bosnia and Herzegovina, Sarajevo, Bosnia and Herzegovina, September 2018.

Research Ethics and Patient's Consent: The study was conducted according to the World Medical Association Declaration of Helsinki. The authors obtained the patient's family approval for case publishing.

\section{Reference}

1. Nicoll R. Environmental Contaminants and Congenital Heart Defects: A Re-Evaluation of the Evidence. Int J Environ Res Public Health. 2018;15(10):2096.

2. Begic Z, Dinarevic SM, Pesto S, Begic E, Dobraca A, Masic I. Evaluation of Diagnostic Methods in the Differentiation of Heart Murmurs in Children. Acta Inform Med. 2016;24(2):94-8.

3. Begic Z, Pandur S, Omerbasic E, Kadic A, Halimic M. Evaluation of Congenital Heart Defects Treatment Options-Establishment of Pediatric Cardiology/Cardiosurgery in Bosnia and Herzegovina. Mater Sociomed. 2017;29(1):73-5.

4. Moodie DS. Adult congenital heart disease. Ochsner J. 2002;4(4):221-6.

5. Xie D, Fang J, Liu Z, Wang H, Yang T, Sun Z, et al. Epidemiology and major subtypes of congenital heart defects in Hunan Province, China. Medicine (Baltimore). 2018;97(31):e11770.

6. Medjedovic E, Begic Z, Stanojevic M, Begic E, Iglica A, Begic N, et al. Ultrasound in the Service of Early Diagnosis and Treatment of Congenital Heart Defects: Bosnian and Herzegovinian Experience. Donald School J Ultrasound Obstet Gynecol. 2020;14(2):131-5.

7. Baumgartner H, Bonhoeffer P, De Groot NM, de Haan F, Deanfield JE, Galie N, et al. ESC Guidelines for the management of grown-up congenital heart disease (new version 2010). Eur Heart J. 2010;31(23):2915-57.

8. Ferro G, Murthy R, Sebastian VA, Guleserian KJ, Forbess JM. Single-Center Experience with the Senning Procedure in the Current Era. Semin Thorac Cardiovasc Surg. 2016;28(2):514-20.

9. Hraska V, Duncan BW, Mayer JE Jr, Freed M, del Nido PJ, Jonas RA. Long-term outcome of surgically treated patients with corrected transposition of the great arteries. J Thorac Cardiovasc Surg. 2005;129(1):182-91.

10. Graham TP Jr, Bernerd YD, Mellen BG, Celermajer D, Baumgartner $\mathrm{H}$, et al. Long-term outcome in congenitally corrected transposition of the great arteries: a multi-institutional study. J Am Coll Cardiol. 2000;36:255-61.

11. Yutzey KE. Cytokinesis, Beta-Blockers, and Congenital Heart Disease. N Engl J Med. 2020;382(3):291-3. 